\title{
A Comparative Study of ISO/IEC 17065:2012 Standards, Accreditation Processes Implemented in Turkey Regarding Turkish Organic Agriculture Legislations
}

\author{
Füsun Zehra Özkan \\ Department of Gastronomy and Culinary Arts, Faculty of Applied Sciences, Altınbaş University, Istanbul, Turkey \\ Email: fusun.ozkan@altinbas.edu.tr
}

How to cite this paper: Özkan, F.Z. (2021) A Comparative Study of ISO/IEC 17065:2012 Standards, Accreditation Processes Implemented in Turkey Regarding Turkish Organic Agriculture Legislations. Agricultural Sciences, 12, 387-405.

https://doi.org/10.4236/as.2021.124025

Received: February 24, 2021

Accepted: April 16, 2021

Published: April 19, 2021

Copyright $\odot 2021$ by author(s) and Scientific Research Publishing Inc. This work is licensed under the Creative Commons Attribution International License (CC BY 4.0).

http://creativecommons.org/licenses/by/4.0/

\section{(c) (i) Open Access}

\begin{abstract}
In this study, the ISO 17065:2012 Conformity Assessment-through comparisons between the required standards for organizations that provide certifications towards products, processes, and services, and the programs regarding the certification of organic agricultural practices in Turkey that are regulated by Turkish Regulations on Principles and Implementation of Organic Agriculture, some recommendations are developed for applications in similar countries, by investigating the similar or contradictory issues surrounding the conformity assessment activities with the regulations published in this field. To contribute to the management and improvement of the certification and accreditation processes of the conformity assessment bodies carrying out the certification activities of the agricultural certification programs within the scope of the ISO 17065:2012 standard, the degree of compliance has been identified by comparing the requirements of the Regulations on the Principles and Implementation of Organic Agriculture. The compatibility of these documents and the absence of conflict in these practices will provide a sense of confidence for all relevant parties, including consumers benefiting from the organic market. According to the conclusions of this evaluation, comparison results were interpreted, taking into account the degrees of compliance from the perspectives of the Ministry of Agriculture and Forestry of the Republic of Turkey that carries out the provisions of the Regulation on the Principles and Implementation of Organic Agriculture, the Turkish Accreditation Agency (TURKAK) that carries out accreditation activities according to the Regulation, and the certification bodies that are the implementers of the standards mentioned above and regulations, the problem areas were determined, and recommendations have been developed. The national problems in this context have been specified, and recommendations were devel-
\end{abstract}


oped based on observations and examinations of ISO 17065:2012 international standard.

\section{Keywords}

Accreditation, Certification, Organic Product, Standardization

\section{Introduction}

Today, in parallel with the rapid change in lifestyle, technology and dietary habits of people all over the world, the change in the production processes of agricultural products and inputs and the effects of these processes on the environment and human health have become increasingly important. In addition to meeting the variable consumer demands in agricultural products, it has also become necessary to provide confidence to all relevant parties in different criteria for agricultural products. In this context, factors such as the increase in environmental and health concerns and the development of socio-economic conditions have greatly increased the need for sustainable agriculture systems such as organic agriculture and good agricultural practices [1].

The increasingly growing global market for organic food in recent years and the rapid spread of organic farming activities all over the world, has created great opportunities for countries to develop organic farming, based on the export potential such as Turkey [2].

Turkey, as a country that is very strategic importance to agricultural production, both in the domestic market share of organic production, and export share is increasing. This situation has brought an accreditation to the agenda that will ensure that the qualifications of the certification bodies are evaluated and approved according to international standards in all agricultural certification programs such as organic agriculture [3].

In addition, the control and application criteria of agricultural certification programs such as organic agriculture are updated in accordance with today's conditions and the need for effective inspection. This program with activities of organic agriculture is considered to be one of the agricultural certification programs in Turkey from the Ministry of Agriculture and Forestry. The organic agriculture law and related regulations published by the Ministry are implemented by the producers and the conformity assessment bodies involved in the inspection process. In this study, in order to contribute to the management of certification and accreditation processes within the scope of the ISO 17065:2012 standard and to contribute to the improvement of these processes, the compliance level of the basic legislation and the requirements of the ISO 17065:2012 standard has been investigated. The compatibility of these documents and their absence of conflict in practices will provide confidence for all relevant parties, including consumers benefiting from the organic market. In European Union or countries that have their own organic agriculture legislation, although the main 
purpose and system are similar, there are different practices such as the use of different inputs and status differences. However, when the issue is evaluated in terms of conformity assessment activities, despite differences in legislation and differences in practice in countries, the importance of the degree of compliance with the ISO 17065:2012 standard and the degree of compliance with this legislation is clear in terms of the effectiveness of the audit system and the production of safe agricultural products. In this context, the legislation published for the certification of organic agricultural products in Turkey and the accreditation of these activities has been evaluated in terms of ISO 17065:2012 standard. By determining the degree of compliance of legislation and standard; recommendations have been made for future legislative updates.

\section{Organic Farming Activities in Turkey}

Organic agriculture started in Europe and the United States of America (USA) for the first time based on certification and then spread to other countries. The growing interest in organic agriculture in Turkey is due to the increase in demand in domestic and foreign markets by raising awareness about the health of consumers. As a result of the increase in consumer demand for organic agriculture and food products, the number of producers who adopt organic agriculture has naturally increased. The growth of this demand has also improved international trade. When organic production areas and product diversity are examined, according to the data of the Ministry of Agriculture and Forestry, the product variety and amount are increasing significantly [4].

In this context, the first law on organic agriculture program in Turkey was established in 2004, taking into account international practices. Turkish Organic Agriculture Law No. 5262 entered into force with the official gazette dated 01.12.2004. The purpose of the law is "to determine the principles and procedures for taking the necessary measures to ensure the development of the production of organic products and inputs in order to offer reliable and quality products to the consumer". The scope of the law has been determined as "Fulfillment of control and certification services related to the execution of organic farming activities and the inspection procedures and principles of the Ministry and the issues regarding powers, duties and responsibilities" [5].

In order to make a comparison with the international standard, within the scope of the relevant law, the definition of the Control and Certification Bodies responsible for organic agriculture activities and controlling of these activities and other relevant definitions are given as follows;

- "Organic agriculture activities: Producing or growing organic products or inputs using soil, water, plants, animals and natural resources, collecting products from natural areas and sources, harvesting, cutting, processing, sorting, packaging, labeling, preservation, storage, transportation, marketing, import, export and other operations of the product until it reaches the consumer" [5]. 
- "Control and certification body: Natural or legal persons authorized by the Ministry to control and certify all stages of the organic product or from its production to the consumer" [5].

- "Authorized body: Natural or legal persons authorized by the Ministry as a control and certification body, control body or certification body" [5].

- "Control activity: It defines the determination of whether organic farming activities are carried out in accordance with this Law, keeping regular records, reporting the results, testing the organic quality of the product with laboratory analyzes if deemed necessary" [5].

Statement of accreditation is defined by the Turkish Accreditation Agency as "to be able to support the reliability and validity of the studies carried out by the accreditation conformity assessment bodies and thus the conformity confirmation documents (test and inspection reports, calibration certificates, management system documents, product documents, personnel documents, etc.)" [6].

The procedures and principles regarding organic farming activities are determined in the Regulation on the Principles and Application of Organic Agriculture dated 18.08.2010 and numbered 27676 issued by the Ministry of Agriculture and Forestry of Republic of Turkey. Seven changes were made to this regulation, the last one was in 2020.

The purpose of the regulation is "to determine the procedures and principles regarding the protection of the ecological balance, the conduct of organic agricultural activities, the regulation, development and dissemination of organic agricultural production and marketing" [7]. Its scope is; "Producing or supplying all kinds of plant, animal and fishery products in accordance with the organic farming method, producing or supplying the inputs to be used in accordance with the organic farming method, yeast used as food or feed, collecting products from forests and natural areas in accordance with the principles of organic agriculture, processing, packaging, labeling and storing these products and transportation, marketing, control, certification, inspection and technical and administrative issues related to penal provisions" [7]. The purpose of these laws and regulations which apply to organic agriculture activities in Turkey are in a conflict with programs in other countries. In global world, especially considering the international trade of agricultural products, it is clear that technical barriers arise when there are different practices and legal sanctions between countries.

Inspection activity within the scope of the regulation is defined as "all kinds of audits of authorized organizations, enterprises and entrepreneurs, controllers and certifiers by the Ministry or the organizations authorized by the Ministry to determine whether organic farming activities are carried out in accordance with this Regulation." Control body is defined as "Real or legal persons authorized by the Ministry to control all stages of the organic product or input from its production until it reaches the consumer", Control and certification body is defined as "real or legal persons authorized by the Ministry to control and certify all stages of the organic product or input from its production to the consumer" [7]. 
On the other hand, ISO 17065:2012 Conformity assessment-requirements standard for organizations that make product, process and service certification, "The certification of products, processes or services is a means of providing assurance that they comply with the conditions specified in the standards and other normative documents." gives the parties as follows:

- "Customers of certification bodies,

- Customers of organizations that certify products, processes or services,

- Official authorities,

- Non-governmental organizations,

- Consumers and other public sector members" [8].

The standard also states that "certification bodies ensure that the certification programs operate in an adequate, consistent, and impartial manner, thus facilitating the recognition of such organizations and the national and international acceptance of certified products, processes and services, and as a result, the conditions intended for the advancement of international trade". Regarding the "Certification Programs" in the ISO 17065:2012 standard, the requirements for the certification programs are not determined by this standard and it is not intended to restrict the roles or choices of the program owner organizations such as the Ministry of Agriculture and Forestry, but the program conditions do not conflict with any requirement of this standard or any standard It is stated that the issue of not excluding the condition in practice is adopted as a principle [8].

The "Certification Body" indicated in the ISO 17065:2012 standard corresponds to the "Control and Certification Organization" in the Regulation on the Principles and Application of Organic Agriculture. At the same time, we can give examples of certification programs applied in the agricultural field such as Good Agricultural Practices, Organic Agriculture, Global G.A.P to the certification programs specified in the standard. EU Organic Farming Regulations in other agricultural products certification programs implemented in Turkey, the US National Organic Program (NOP) and Japanese Agricultural Standard (JAS) stand out. In addition, there are certification programs applied outside of agricultural production.

\section{Comparison of the Standards of ISO 17065:2012 Conformity Assessment-Requirements for Product, Process and Service Certification Organizations with the Regulations Regarding the Principles and Implementation of Organic Agriculture in Terms of Certification Activities}

ISO 17065:2012 Conformity assessment-When examining the requirements standard for organizations that make product, process and service certification and the Regulation on the Principles and Application of Organic Agriculture, the parties benefiting from the implementation of the certification program are similar. 
In the ISO 17065:2012 standard, Terms and Definitions are given within the scope of article 3.; customer, consultancy, product requirements, certification program, certification scope, program officer, certification body, impartiality, evaluation, product, process, service, certification requirement. In the Regulation on the Principles and Application of Organic Agriculture, directly related to the mentioned standard and accreditation activities; Inspection, Control, Control and Certification Body, Certificate, Certification, Inspector, Certifier, Certificate of Conformity, Authorized Body, Committee, Organic Herbal production, Organic Animal production, Organic Aquaculture production etc. definitions are included.

The certification statement in the ISO 17065:2012 standard corresponds to the certification in the Organic Agriculture Regulation, the Certification Body Control and Certification Body/Authorized Body, the Assessment statement Control, Certification Program Organic Agriculture activities, and the Program Officer to the Ministry of Agriculture and Forestry of Republic of Turkey.

Within the scope of conformity assessment activities of the Turkish Organic Agriculture Law No. 5262 and the Regulation on the implementation of the law, the concept of accreditation and its relationship with the ISO 17065:2012 standard is primarily included in the 11th article, "The Ministry has been accredited partially or completely, when deemed necessary; can be transferred to public institutions and organizations, private sector legal entities and universities".

In this study, the relationship of the law and regulation, whose objectives and scopes are outlined above, have been examined with "product certification activity within the scope of organic production", one of the conformity assessment activities; certification and accreditation activities while taking into account the activities of the Authorized Bodies/Certification and Control Bodies and the Accreditation Agency in order to be able to examine the applications in Turkey.

\subsection{The Connection of the Organic Agriculture Certification Program with the ISO 17065:2012 Standard and the Requirement of Accreditation}

Although accreditation activities are based on volunteering, accreditation may become mandatory within the scope of the legislation regulating the certification program for agricultural products such as organic agriculture.

In Turkey, according to the Law No. 5262 and the Regulation issued based on this law, organic agriculture certification is divided into two as control and certification procedures, and these operations are carried out by control and/or certification bodies authorized by the Ministry of Agriculture and Forestry. Certification and control bodies must be accredited by the Turkish Accreditation Agency or the European Accreditation Association according to the mutual recognition agreement according to the ISO/IEC 17065:2012 standard.

Those that are not within the scope of accreditation body; there is not any accreditation provision in the fields of activity related to fertilizers, soil improvers, 
nutrients and plant protection substances to be used in organic agriculture. Authorization in this area is made by the Ministry of Turkey. Certification bodies are given a maximum period of thirty months from the date they are authorized by the Ministry for accreditation. In addition, until it is accredited, it is allowed to make one-year contracts with at most ten entrepreneurs, including the producers in the group, for each field of activity. In case this period is exceeded, the work permit is canceled by the Ministry in scopes where the authorized institution is not accredited.

Within the scope of the Regulation on Principles and Application of Organic Agriculture, there are statements that the Control and Certification activities will be carried out by the Ministry or by the control and certification bodies authorized by the Ministry, and also that the relevant control activities will be carried out according to international standards, and reference is made to standards for product certification within the scope of conformity assessment activities.

The comparison of the mentioned regulation and standard has been examined in this section by considering the main articles of the ISO 17065 Conformity assessment-Based on the basic provisions of the requirements (ISO/IEC 17065:2012) standard for organizations that have product, process and service certification, Turkish Organic Agriculture Regulation, which is considered as a certification program, has been compared. Summary information regarding the comparison is given in Table 1 at the same time considering the basic items.

\subsubsection{Comparison of ISO 17065:2012 Standard under General Conditions}

In accordance with the mentioned regulation with inspection and certification organizations of the Turkish Accreditation Agency or the European Accreditation by the mutual recognition agreement validity of existing international accreditation to be accredited to the requirements of the institutions and accredited abroad, if a foreign organization opens a branch in Turkey, Turkish Accreditation Agency or European Accreditation to the mutual recognition agreement, the Accreditation Association has made a regulation that it is required to submit the accreditation document indicating that it is accredited from the existing international accreditation institutions.

Within the scope of the General Conditions article of the standard; Minimum requirements have been determined for six basic issues: legal and contractual issues, management of impartiality, liability and financing, non-discriminatory conditions, confidentiality, and publicly available information. When the relevant regulation regarding the fulfillment of these conditions is examined, the articles of the regulation below are reached.

Regarding legal and contractual matters, Regulation determines the name, address, capacity information, and documents pertaining to the legal status of the enterprise, the date of the contract, the text of the contract signed, the date of the transition to organic agriculture started, information on the land history and 
Table 1. ISO/IEC 17065:2012 conformity assessment-regulations on the principles and implementation of organic agriculture No.27676, corresponding to the provisions of the standard for product, process and service certification.

ISO/IEC 17065:2012 Conformity assessment The Organic Agriculture Law No. 5262 and the -Requirements for bodies certifying Regulation on the Principles and products, processes and services Implementation of Organic Agriculture dated 18.08.2010 and numbered 27676

*In the table, regulation article numbers are defined as Item, law article numbers are defined as Law Item

\section{Preface}

\section{Introduction}

1. Scope

2. Referenced standard and documents

3. Definitions

4. General Requirements

4.1. Legal and contractual matters

4.2. Management of impartiality

4.3. Liability and financing

4.4. Non-discriminatory conditions

4.5. Confidentiality

4.6. Publicly available information

5. Structural Requirements,

Organizational structure and top management

5.1. Mechanism for safeguarding impartiality

6. Resource Requirements

6.1. Certification body personnel

6.2. Resources for evaluation

7. Process Requirements

7.1. General
Item 4

Item 2

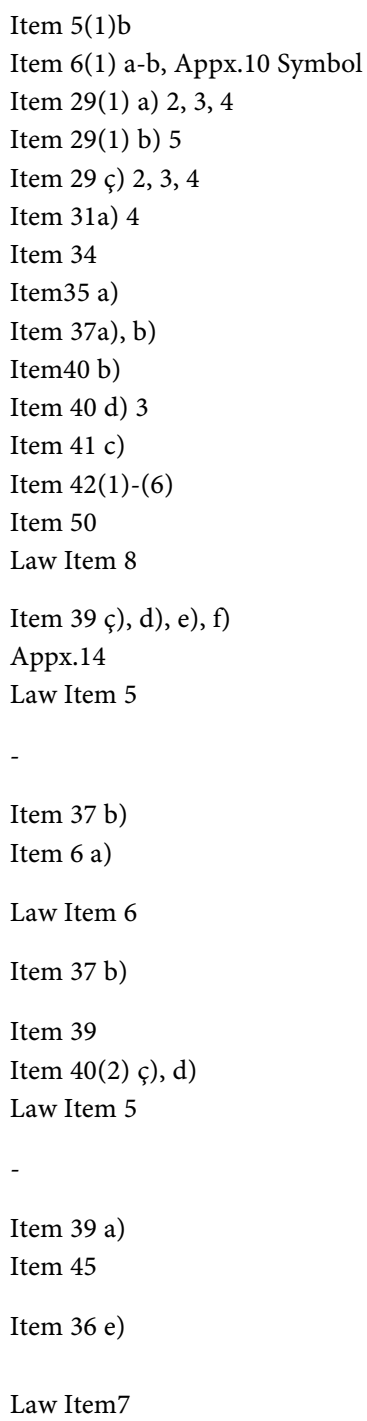




\section{Continued}

7.2. Application

Item 6 a)

Item $9 \mathrm{f}), \mathrm{g}$ )

Item 32e)

Item 35a)

7.3. Application review

Item 35

Item 35

Item 36

7.4. Evaluation

Item 37a)

Item $41 \mathrm{~h}$ )

Item 426 a)

7.5. Review

Item $41 c ̧)$

Item 33

Item 37

7.6. Certification decision

Item 38

Item 41ç)

Law Item 5

Item $4 \mathrm{z}$, ee

Item $9 \mathrm{f}$ ), g)

Item 11 ç)

Item 29 a), b)

7.7. Certification documentation

Item $31 \mathrm{~b}$ )

Item 32 b), c)

Item 40(3)

Item $41-c$

Appx.11

Item $4 \mathrm{z}$ )

7.8. Directory of certified products

Item $5 \mathrm{~b}$ )

Item 43

7.9. Surveillance

Item 36 a), b)

Item $42(1)$

Item 43

7.11. Termination, reduction, suspension or withdrawal of certification

Item 42(6) b), c)

7.12. Records

All Items

7.13. Complaints and appeals

Item $40 \mathrm{~d}$ )

Item $41 \mathrm{~g}$ )

Item $37 \mathrm{~b}$ )

8. Management System Requirements

Item 38

8.1. Options

8.2. General management system documentation (Option A)

Item 38

Item $40 \mathrm{~d}$ ), e)

8.3. Control of Documents (Option A)

8.4. Control of Records (Option A)

Item $37 \mathrm{~b}$ )

Item 38

All Related Items

8.5. Management review (Option A)

8.6. Internal audits (Option A)

8.7. Corrective actions (Option A)

Item 40(2) d)

Item 42 (6) a), b)

8.8. Preventive actions (Option A) 
legal documents of the legal entity. Likewise, in the regulation regarding the legal personality information of the certification body in the relevant standard, it is stipulated that the certification will be made by the real or legal entities that have received this authorization from the Ministry, and that the control and certification body or certification body that has been given certification cannot transfer its authority to another institution or organization.

In the Regulation, it is stated that organic farming activities will be carried out based on the contract signed between the enterprise and the authorized organization and that this contract refers to the written agreement that states that the agricultural activity will be carried out in accordance with the provisions of this regulation. In addition, the authorized organization within this scope must register the contractor in the data system within 45 days at the latest and notify the Ministry. According to the Regulation, the enterprise who wants to engage in organic farming can do organic farming activities individually as well as with the producer group, and if the enterprise is doing organic farming with the producer group, he must sign a contract with each producer and make a contract with the organization authorized on behalf of the producer group.

In the general conditions section of the standard, the certification body must have a legally valid contract in order to provide certification activities to customers and the obligations of the certification body and customers must be taken into account in the certification contracts, and the obligations that should be within the scope of the contract are detailed in this article of the standard. Therefore, although the provisions of the contract signed between the enterprise carrying out the organic agriculture activity and the control-certification bodies are explained both in the standard and in the regulation, it becomes mandatory for the contract provisions to be in full compliance with the relevant article of the standard in terms of accreditation, except for the obligations of both parties specified in the regulation.

In the standard, the conditions related to the use of license, documents and conformity marks are defined in general within the scope of the same article, and the Certification Program is referred to in order to create a control mechanism as specified in the certification program. In this context, necessary arrangements are made in the law and regulation defining the certification program. In Organic Agriculture Regulation, regarding the use of the logo, the phrase "organic" that can be used on the label, the phrase "transition process", the color, font and writing styles of these phrases, the organic product logo cannot be used on the products of the transition process and the name, logo, code number and product certificate number of the authorized organization. In addition, Article 8 of the Organic Agriculture Law stipulates that the labels and logos of organic products and inputs will only be used for organic products and inputs and cannot be used incorrectly or misleading the consumer.

When the issue is examined in terms of the management of impartiality, the ISO 17065:2012 standard generally documents the fact that certification activi- 
ties should be carried out impartially and the activities for the Control and Certification Bodies have to ensure this impartiality and the issues that may threaten the impartiality. When the Organic Agriculture Law is examined within the scope of the management of impartiality; it can be seen that the relevant article of the ISO 17065:2012 standard in terms of ensuring the impartiality between the control mechanism and the decision mechanism, in which the Control and Certification body will consist of two separate units as control and certification, and those working in the control unit cannot work in the certification unit and those working in the certification unit cannot work in the control unit which is compatible with the management of objectivity.

It has been observed that provisions on impartiality are also regulated by the Organic Agriculture Regulation. In summary, in the regulation; The requirement that authorized bodies should be independent of commercial, financial and other pressures that may affect the results of the certification process, Authorized organizations have to be impartial that they cannot be in any conflict of interest when using the authority given to them, that they cannot supply and design the product types they certify, and that they cannot provide consultancy services. managers, partners, controllers and employees and their first-degree relatives cannot control and certify organic farming activities. In addition, it was clearly stated that the managers, partners, controllers and employees of the organization authorized for impartiality cannot work in another authorized institution at the same time, and those working in the control unit cannot work in the certification unit and those working in the certification unit cannot work in the control unit.

In addition to the standard regulation, it emphasizes the need to identify and monitor risk areas for impartiality and to establish a neutrality commitment by senior management. Under the confidentiality principle, when the Organic Agriculture Law is examined; It is stated in Article 6 that the authorized institutions cannot give the information and documents they obtain to third parties other than the Ministry. The relevant article of the law does not conflict with the confidentiality issues emphasized in the standard.

Publicly available information includes regulations regarding the use of the logo and pricing regulations. In addition, it was stated that the regulation regarding the objections and complaints is under the authority of the Ministry. In this context, it is seen that a public method is not recommended.

A special regulation regarding the liability and financing, public information and non-discriminatory conditions within the scope of the General Conditions article of the ISO 17065 standard is not included in the Organic Product Law and the relevant regulation.

\subsubsection{Comparison of ISO 17065:2012 Standard under Structural Conditions}

Within the scope of the ISO 17065:2012 standard Structural Conditions clause, the organizational structure of the certification bodies and the minimum condi- 
tions are determined for the use of a mechanism to ensure impartiality and neutrality. When the Organic Agriculture Law and related regulations are examined within the scope of this article; the structuring process of the organizations authorized for impartiality and the separation of control and certification units are clearly stated and their organizational structure and job descriptions are specified as documents regarding the place and organization definitions of these organizations. Although it is included in the standard, there is no separate provision in the regulation on the formation of a mechanism to ensure impartiality.

\subsubsection{Comparison within the Scope of ISO 17065:2012 Standard Resource Conditions}

Within the scope of the ISO 17065:2012 standard Resource Conditions clause, the minimum requirements for the certification body personnel, the competence of the personnel and the availability and competence of internal and external resources are determined. In this context, when the Organic Agriculture Regulation is examined, in parallel with the aforementioned Standard in the regulation, the organizational structures of authorized organizations should be defined, their job descriptions should be determined, they should have the technical and administrative opportunities to fulfill their duties, the minimum number of controllers and certifiers that should be employed and their qualifications were determined.

In the regulation, it is stated that if product samples are taken for analysis, they should be analyzed in laboratories accredited according to the ISO 17025 standard, although it does not conflict with the relevant article of the standard, objectivity, confidentiality, personnel qualifications, etc. There are additional conditions for the fulfillment of additional conditions by authorized bodies.

\subsubsection{Comparison within the Scope of ISO 17065:2012 Standard Process Conditions}

It refers to the "Certification Program" carried out by the authorized organizations under standard process requirements. When the regulation is examined within the scope of the Certification Program; the application conditions, the method of how the control will be carried out, the conditions for transition to organic production, the acceptance conditions as an organic product, the issues that the authorized organization should approve, the issues that the authorized organization should be informed by the operator, the certification conditions, the information that should be included in the certification documents (certificate of conformity) as a minimum. It is seen that the records required by the authorized institutions and entrepreneurs in the operation of the certification program, the information and documents that should be notified to the Certification Program Director, the notification of changes and the audit mechanisms.

In the regulation, it is emphasized that the characteristic of organic production is that every stage of production is controlled, and the product is certified, and it has been found in accordance with the general objectives of the standard. 
In accordance with the decision article of the standard, the authorized body will be responsible for its decisions regarding certification, will keep the authority for these decisions and cannot transfer it, in parallel with the standard requirement in the regulation.

Although it is clearly defined in the regulation that the organic product certificate will be given by the certification, there is no regulation regarding the review activity before the certification decision within the scope of the evaluation article of the standard.

In the Regulation, the method determined that the Ministry has the authority to investigate and request new documents in case of objection and complaint to the sanctions deemed appropriate by the authorized institution, to examine the information and documents related to the objection and complaint and to make the final decision and to convey the result to the parties. What is requested from the organizations authorized by the Standard is that the objection or complaint is examined and concluded by impartial and competent persons after determining that it is related to the relevant certification activity, to prevent situations that may create conflict of interest, to keep the necessary records and to define these processes.

Regarding the surveillance activities in the standard, the regulation includes an application that can correspond to the surveillance activity in the form of unannounced controls to be applied to all operators under the contract during the validity of the certificate.

\subsubsection{Comparison within the Scope of ISO 17065:2012 Standard Management System Requirements}

With the $8^{\text {th }}$ article of the ISO 17065 standard, it is a condition for certification bodies to establish and maintain a management system. Within this scope, one of the two types of management systems, Options A and B, can be selected by certification bodies. With Option A, the certification body's management system includes Handbook, General management system documentation, Document control system, Control of Records, Management review activity, Internal audit activity, Corrective and Preventive activities. Option B is foreseen for Certification Bodies that have created and maintained a management system in accordance with the requirements of the ISO 9001 Quality Management System Standard.

When the Organic Agriculture Regulation is examined, it will be presented to the Ministry by creating a certification system that includes information about the price list applied by the certification bodies, certificate sample, testing and inquiry method, analysis method, all techniques and documentation system used, and also explains the quality system according to the nature of the work done. It is stated that a Quality Handbook will be prepared. It is seen that the Corrective and Preventive activities specified in the standard's management system requirements include only the area for non-conformities identified for certified operators. In addition, there is no special provision for the evaluation of the 
applied management system by the top management of the authorized institutions.

\subsubsection{Comparison within the Scope of References and Other Matters within the Scope of the Regulation}

Out of standard conditions, the provisions of Article 9 of the Turkish Food Codex Regulation have been directly referred from the Regulation. The information and documents that the institutions authorized to the Ministry as the owner of the Certification Program are obliged to send, are specified in detail within the scope of Article 43 of the Regulation. In addition, the inspections to be made to the institutions authorized by the Ministry and the qualifications of the inspectors who will take part in the inspection are explained within the scope of article 44 of the regulation. Within the scope of Article 47, there are sanctions for administrative fines to be imposed on entrepreneurs and authorized organizations acting in violation of the Law.

The regulation defines two committees responsible for the stages of the law and the implementation of the regulation. Authorized organizations are assigned by the Organic Agriculture Committee within the scope of article 48. On the other hand, Organic Agriculture National Steering Committee is about the implementation and development of organic agriculture, supports and incentives, raising awareness of the consumer, marketing organic products domestically and abroad, determining the problems in practices and determining the strategies in this regard, determining project proposals on organic agriculture and determining research priorities. Those activities have been created within the scope of the relevant regulation to carry out the studies.

\section{Results of Comparisons}

When the certification programs and historical development regarding the implementation of the certification activities of agricultural products in Turkey are examined; it can be seen from the mentioned certification programs that activities related to organic agriculture started in the 1980s. The organic farming activities subject to certification were first implemented since 1991, based on the European Union Organic Agriculture Regulation No. 2092/91. Until 2004, two regulations on organic agriculture were published by the Ministry of Agriculture and Forestry and the Organic Agriculture Law came into force in 2004. The contribution of organic agriculture to future generations is of great importance in terms of efficient use of our natural resources and keeping them clean and protecting biological diversity [9].

Certifications and assessments made within the scope of certification programs for agricultural products such as good agricultural practices and organic agriculture are carried out within the scope of conformity assessment activities. In Turkey organizations that carry out certification activities within the scope of ISO 17065:2012 Conformity Assessment-Requirements for Institutions that Perform Product, Process and Service Certification and are authorized by the 
Ministry of Agriculture and Forestry of Republic of Turkey are accredited by the Turkish Accreditation Agency (TÜRKAK). Although accreditation is a prerequisite for each certification program, conditions are defined for the accreditation process of organizations authorized under the relevant regulation of each program. The basic criteria taken as basis in the accreditation process are the requirements of the ISO 17065:2012 standard and the regulations for the relevant certification program [9].

In addition, accreditation is carried out by taking into account the scope of the product certification bodies in their fields of activity according to the R50.07 Rules Guide for the Accreditation Processes of Agricultural Products Certification Institutions published by the Turkish Accreditation Agency [10].

ISO 17065:2012 Conformity Assessment-Requirements for Product, Process and Service Certification Establishments, certification is defined as a third-party conformity assessment activity and is described as "the degree of trust and belief in showing that the specified conditions are met, by a third party with impartiality and competence" and it determines the general criteria for organizations operating various certification programs [8].

When the Organic Agriculture Regulation and the relevant standard used for accreditation are examined, as can be seen in Table 1, except for some articles of the standard, the regulation and its annexes which are applicable in Republic of Turkey defining the certification program and the certification program definition in the standard and the activities in the fulfillment of the certification are not inconsistent. The standard specifies the minimum requirements that must be met by the organizations that will carry out certification activities in this field for products, processes and services, and draws a framework for the establishment of the infrastructure.

ISO 17065:2012 Standard can be applied by all organizations that make product certification. When the law and the relevant regulation are examined, it has been determined that the standard covers the basic principles of the standard such as accreditation connection and impartiality, confidentiality, especially the sectoral conditions for the certification program referred to in the process requirements article. Details for this comparison can be seen in Table 1.

Table 1 within the scope of ISO 17065:2012 standard requirements of the comparison results with regulatory requirements applicable in Turkey are given below.

- In the Regulation, it has been determined that there is no specific regulation regarding the Obligation and Financing, Internal Audits and Management Review activity and the Impartiality Mechanism specified as a condition in the standard.

- Within the scope of Public Information, regulations regarding the use of logo and regulations regarding pricing are included in the regulation, it has been stated that the final decision regarding the objections and complaints is under the authority of the certification program owner. In this context, it is seen 
that a method that is open to the public is not clearly recommended.

- A special regulation regarding liability and financing, publicly available information and non-discrimination conditions within the scope of the General Conditions article of ISO 17065:2012 standard is not included in the Organic Agriculture Law and the relevant regulation.

- In the use of outsourcing included in article 6.2 of the ISO 17065:2012 standard, besides informing the certified parties (entrepreneurs), it is seen that the measures for the protection of confidentiality and impartiality are not regulated in detail in the relevant legal legislation, especially when there are different methods such as tenders in the acceptance of customers by certification bodies.

- However, although there is a regulation under the title of liability and financing in article 4.3 of ISO 17065:2012 standard, there are no clear provisions on this subject in organic agriculture legislation.

- There is an application in organic agriculture legislation that can correspond to surveillance activities in the form of unannounced controls during the validity period of the certificate, it has been determined that these activities are not exactly compatible with the relevant standard.

Soever it is clearly defined in the regulation that the organic product certificate can be issued by the certifier, there is no specific regulation regarding the review activity before the certification decision within the scope of the evaluation article of the standard.

\section{Conclusions and Suggestions}

As a result of comparing the legislation and international standard requirements for the organic agriculture certification program applied in Turkey, a detailed examination of incomplete or contradictory issues was conducted. By evaluating the results of the comparison, suggestions have been developed for both the legislative and auditing parties.

In recent years, there has been a significant increase in the number of organizations authorized by the relevant ministry in the scope of good agricultural practices and organic agriculture in Turkey. There is no limit to the number of producers and enterprises and these organizations will be certified after they become accredited. Regulating the obligations and financing conditions of the certification bodies with the legislation will contribute to the strengthening of the system in order not to experience grievances for third parties in addition to the products certified in the future. Although there is a regulation under the title of liability and financing in article 4.3 of the ISO 17065:2012 standard, there are no clear provisions on this subject in organic agriculture legislation. An explanatory regulation on the lower and upper limits of professional liability insurance applied by certification bodies and insurance coverage will be useful.

Within the framework of the article 7.9 of the ISO 17065:2012 standard, taking into account that the use of the logo on the packaging of the certified prod- 
uct is allowed, the surveillance policies of the certification bodies should be established. Although there is an application in the organic agriculture legislation that can correspond to the surveillance activity in the form of unannounced controls during the validity period of the document, these activities need to be further strengthened in line with the relevant standard.

It is proposed that the regulations on obligations and financing, public information and non-discriminatory conditions contained in the general terms of ISO 17065:2012 standard should be taken into account first within the scope of the changes to be envisaged in the legislation. It is recommended that clear statements be included in the legislation for non-discriminatory conditions. As far as methods are concerned, it is recommended that clear statements should be included in the legislation for these situations.

Additionally, regulating the issues related to the management of the competence of the personnel in the certification process included in the article 6.1 of the ISO 17065:2012 standard in the relevant legislation to determine the competence of the personnel in this field according to the scope of agricultural production will strengthen the inspection and control system.

In addition to informing the certified parties in outsourcing in article 6.2 of the ISO 17065:2012 standard, the detailed regulation of the measures for the protection of confidentiality and impartiality with the legal legislation will provide confidence for all interested parties.

The legislation includes provisions for the execution of control activities in the enterprise or warehouse of the manufacturer or entrepreneur. On the other hand, after the certification, a surveillance activity that will be carried out periodically at sales points where the organic agriculture logo is used or in organic markets will increase the compliance of the regulation with the relevant standard.

In addition, although it is clearly defined in the Regulation that the organic product certificate can be given by the certifier, there is no specific regulation for the review activity before the certification decision within the scope of the evaluation article of the standard. This issue can be misinterpreted by authorized organizations in practice. It has been concluded that a regulation that will enable organizations to evaluate the relevant activity as a separate sub-process before certification will increase compliance with the relevant standard and strengthen impartiality.

In the revision stages of the regulation on the implementation of the Organic Agriculture Law, apart from the certification and control organizations, which are the individual implementers of the regulation, the active involvement of the functions involved in the accreditation processes by the Accreditation Agency, especially the issues that arise during the implementation of the accreditation audit processes, effectively as feedbacks. It is thought that submitting it to the Ministry and evaluating it by the Ministry and reflecting it on the regulations and practices will strengthen the certification program. In addition, the prepara- 
tion, modification, revision of the regulation, etc. by periodically informing the Ministry's experts involved in the processes about the accreditation standard and accreditation processes; it was believed that the participation of experts actively involved in these processes in the audit processes would improve the system.

It is obvious that synchronization of both control mechanisms will prevent time and financial losses for the practitioners and the Ministry as the executor of the certification program, since there are similarly examined issues in the inspection mechanism carried out by the Ministry against the sanctions within the scope of the regulation and in the accreditation audits. At the same time, it will ensure the elimination of contradictory situations that may occur between the inspections in terms of authorized institutions and in case of any negative consequences such as suspension or withdrawal of the certificate, it will facilitate parallel practices by the Ministry and the accreditation body.

Considering other countries that have agricultural certification programs and the practices in the world, it is a necessity for the legislators to reflect the logic of conformity assessment standards into the legislation and to take the necessary measures to eliminate contradictory areas, especially in order to facilitate international trade and to spread similar and good practices, while focusing on the needs of all relevant parties.

The main objective of the legislation on organic agriculture applied in Turkey and other countries, especially when conformity assessment considered product certification and accreditation activities from its activities, the ISO 17065:2012 logic of Standards and not in conflict with the minimum requirements is of utmost importance. For the parties that prepare the legislation in countries that carry out these processes based on accreditation, the parties that are their implementors and all parties that carry out and deal with product certification and accreditation activities in this field; It is recommended to know the requirements of the ISO 17065:2012 standard and to reflect them in national legislation in order to reduce the differences between countries.

Moreover, while carrying out periodic review and revision activities of international standards used in this field, it is recommended to take the opinions of the owners of the agricultural certification programs applied at the national scale, especially in order to eliminate the problems experienced in the practices. In addition, the similarities in national certification programs should be reflected in the relevant international standards or the preparation of a sectoral guide to which the ISO 17065:2012 Standard will be referred to by the International Standard Organization (ISO) will be an important guide in establishing and updating national legislation based on accreditation for agricultural certification programs and agricultural certification. An opinion has been formed that it will reduce international differences in its activities.

\section{Conflicts of Interest}

The author declares no conflicts of interest regarding the publication of this paper. 


\section{References}

[1] Eryılmaz, G.A., Kılıç, O. and Boz, İ. (2019) Türkiye'de Organik Tarım ve İyi Tarım Uygulamalarının Ekonomik, Sosyal ve Çevresel Sürdürülebilirlik Açısından Değerlendirilmesi. Evaluation of Organic Agriculture and Good Agricultural Practices in Terms of Economic, Social and Environmental Sustainability in Turkey, Yüzüncüyıl Üniversitesi Tarım Bilimleri Dergisi, 29, 352-361.

[2] Demiryürek, K. (2011) Organik Tarım Kavramı ve Organik Tarımın Dünya ve Türkiye'deki Durumu. The Concept of Organic Agriculture and Current Status of in the World and Turkey, Gaziosmanpaşa Üniversitesi Ziraat Fakuiltesi Dergisi, 28, 27-36.

[3] Kılıçarslan, N.S. (2015) Tarım ve Orman Bakanlığı AB Uzmanlık Tezi, Türkiye ve AB'de Organik Tarım Mevzuatı, Uygulamaları ve Değerlendirmesi. Organic Farming Legislation, Implementations and Evaluation.

[4] Ministry of Agriculture and Forestry of Republic of Turkey (2021) T.C Tarım ve Orman Bakanlığı.

https://www.tarimorman.gov.tr/Konular/Bitkisel-Uretim/Organik-Tarim/Istatistikl er, Turkish

[5] Turkish Organic Agriculture Law No. 5262 (2004). https://www.mevzuat.gov.tr/MevzuatMetin/1.5.5262-20100311.pdf

[6] Turkish Accreditation Agency (2021). https://www.turkak.org.tr/

[7] Regulation on the Principles and Implementation of Organic Agriculture Dated 18.08.2010 and Numbered 27676.

https://www.resmigazete.gov.tr/eskiler/2010/08/20100818-4.html

[8] ISO/IEC 17065:2012 Conformity Assessment-Requirements for Bodies Certifying Products, Processes and Services (2012).

https://www.iso.org/obp/ui/\#iso:std:iso-iec:17065:ed-1:v1:en

[9] Özkan, F.Z., Hasdemir, M. and Uzunçam, R. (2015) Türkiye'de Tarım Ürünlerinin Belgelendirilmesi ve Akreditasyonu. Certification and Accreditation of Agricultural Products in Turkey, Tarım Ekonomisi Araştırmaları Dergisi, 1, 48-58.

[10] R50.07 Tarım Ürünleri Belgelendirmesi Yapan Kuruluşların Akreditasyon Süreçlerine İlişkin Kurallar Rehberi. Guidelines for Accreditation Processes of Agricultural Products Certification Bodies (2019).

https://secure.turkak.org.tr/docs/GuiedeLines/R50-07 04 0.pdf 